\title{
The biology and potential for genetic research of transposable elements in filamentous fungi
}

\author{
Léia Cecilia de Lima Fávaro ${ }^{1}$, Welington Luiz de Araújoํㄹ , João Lúcio de Azevedo ${ }^{3}$ and \\ Luzia Doretto Paccola-Meirelles ${ }^{1}$ \\ ${ }^{1}$ Universidade Estadual de Londrina, Centro de Ciências Biológicas, Departamento de Biologia Geral, \\ Laboratório de Genética de Microrganismos, Londrina, Paraná, Brazil. \\ ${ }^{2}$ Universidade de São Paulo, Escola Superior de Agricultura Luiz de Queiroz, Departamento de Genética, \\ Piracicaba, São Paulo, Brazil. \\ ${ }^{3}$ Universidade de Mogi das Cruzes, São Paulo, Brazil.
}

\begin{abstract}
Recently many transposable elements have been identified and characterized in filamentous fungi, especially in species of agricultural, biotechnological and medical interest. Similar to the elements found in other eukaryotes, fungal transposons can be classified as class I elements (retrotransposons) that use RNA and reverse transcriptase and class II elements (DNA transposons) that use DNA. The changes (transposition and recombination) caused by transposons can supply wide-ranging genetic variation, especially for species that do not have a sexual phase. The application of transposable elements to gene isolation and population analysis is an important tool for molecular biology and studies of fungal evolution.
\end{abstract}

Key words: transposable elements, filamentous fungi, genetic application.

Received: August 17, 2004; Accepted: March 22, 2005.

\section{Introduction}

Transposons are mobile genetic transposable elements that can multiply in the genome of eubacteria, archaea and eukaryotes using a variety of mechanisms and were first discovered in maize in the 1940s by Barbara McClintock. Since their initial discovery a growing number of transposons have been detected in bacteria, plants and animals (Finnegan, 1989). Transposons were first identified in fungi in the yeast Saccharomyces cerevisiae (Boeke, 1989), with the first evidence for their presence in filamentous fungi coming from conventional genetic studies with Ascobolus immersus mutants unstable for spore-staining (Decaris et al., 1978).

Advances in genome molecular analysis of the species used as models for fungal genetics (e.g. the ascomycetes Neurospora crassa and Aspergillus nidulans) showed that they contain silenced transposons, the loss of activity of which may be the consequence of continuous selection for phenotypic stability and the action of several mechanisms of genetic silencing which inactivate repeated

Send correspondence to Luzia Doretto Paccola-Meirelles. Universidade Estadual de Londrina, Centro de Ciências Biológicas, Departamento de Biologia Geral, Caixa Postal 6001, 86051-990 Londrina, PR, Brazil. E-mail: paccola@uel.br. sequences, including transposable elements (Selker, 1999; Faugeron, 2000; Cogoni, 2001). More detailed descriptions on the biology of transposons in filamentous fungi have been published especially for species of agricultural, biotechnological and medical interest (see reviews by Oliver, 1992; Kistler and Miao, 1992), although the sexual stage has not been described for most of these species which generally show a high level of genetic variability (Daboussi, 1997; Kempken and Kück, 1998). The study of the transposons in these technologically useful species led to the discovery of many types of elements, covering practically the whole spectrum of transposable eukaryotic elements (Daboussi, 1997; Kempken and Kück, 1998).

Several types of DNA retroelements and transposons are active and induce a variety of modifications and have the potential to influence many aspects of fungal genome evolution. These mutagenic properties have also been explored to develop a gene isolation strategy, known as transposon tagging. The dynamic of these elements includes different mechanisms, such as transposition, ectopic recombination and horizontal transmission. Further, the study of the distribution of transposons in natural populations can provide important ecological and epidemiological data (Daboussi and Capy, 2003). This article will review 
some aspects related to the study of transposons in fungi especially the distribution and classification of these elements, transposition mechanism and consequences for the fungal genome, and the main strategies used to identify new elements and their potential for genetic research.

\section{Transposable Element Structure and Distribution in Fungi}

The transposable elements of fungi are similar to those of eukaryotes in general and can be divided into two main classes according to the mode of transposition and their structural organization (Figure 1). Class I elements (retroelements) which transpose by reverse transcription of an RNA intermediate, this class being subdivided into retrotransposons flanked by long terminal repeats (LTR) and non-LTR retroelements with long dispersed nuclear element structures (LINEs) and short dispersed nuclear element structures (SINEs). Class II elements (DNA transposons) are flanked by two inverted terminal repetitions (TIRs) and transpose directly using the enzyme transposase. Both classes are subdivided into different superfamilies based on the structure, internal organization, size of the duplication of the target site generated after insertion and similarity in DNA and protein sequences (Finnegan, 1989). The International Committee on Taxonomy of Viruses recently proposed a classification for LTR retrotransposons based on the relationships between the amino acid sequences of reverse transcriptase, the most highly conserved of the retrotransposon proteins (Havecker et al., 2004). This classification separates the retrotransposons of animals, fungi, plants and protozoa into two great families, the Pseudoviridae and Metaviridae which are distinguished by the order of the coding regions of structural ( $g a g$ ) and enzymatic ( $p o l$ ) proteins. In the Metaviridae the pol genes are ordered in the sequence protease/reverse transcriptase/RnaseH/integrase while in the Pseudoviridae the order of the pol genes is protease/integrase/reverse transcriptase/RnaseH (Figure 2). In previous revisions (Daboussi, 1996; Kempken and Kück, 1998; Daboussi and Capy, 2003), the classification of the LTR retroelements

Class I elements: RNA intermediate

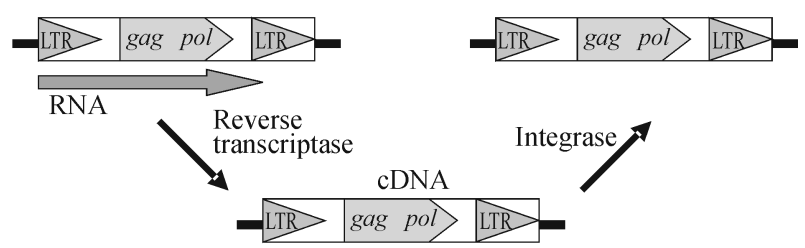

Class II elements: direct transposition

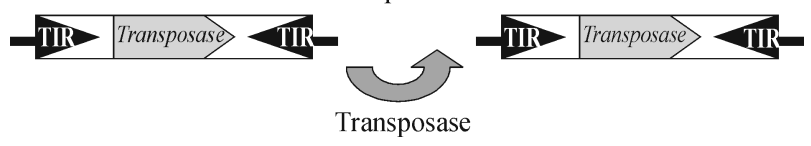

Figure 1 - General structure of transposable elements of eukaryotes (based in Finnegan, 1989).
LTR Retrotransposons

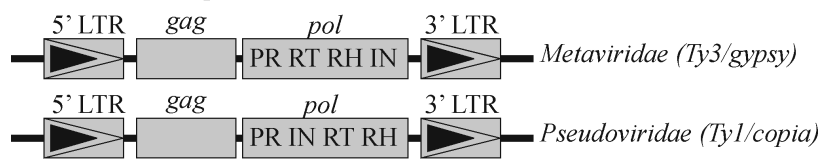

non LTR Retrotransposons

$\begin{aligned} & \text { 3' } \\ & \text { RT } \quad \mathrm{RH}\end{aligned}=$ Poly A LINE like element

Figure 2 - Schematic representations of the structural features of class I transposable elements (based on Daboussi, 1996 and Havecker et al., 2004). Long terminal direct repeat (LTR) retrotransposons resemble retroviruses in having LTRs flanking an internal domain encoding proteins analogous to the gag and pol retroviral gene products. The non LTR-retrotransposons lack terminal repeats and carry a poly (A) tail at their 3' ends. Elements with long dispersed nuclear element structures (LINEs) possess two long open reading frames (ORFs), with similarities to gag as well as the reverse transcriptase (RT) and RnaseH (RH) genes. Elements with short dispersed nuclear element structures (SINEs) are short elements which contain an internal RNA polymerase III promoter with bipartite structure (boxes A and B) and which rely on RT for mobilization but do not themselves encode the enzyme.

was based on their similarity to gypsy elements (equivalent to the Metaviridae) and copia elements (equivalent to the Pseudoviridae).

Thirty class I transposons (retroelements) have already been described including Metaviridae (gypsy) and Pseudoviridae (copia) LTR retrotransposons and retrotransposons without the LINEs and SINEs type LTRs. The gypsy retrotransposons identified to date are shown in Table 1, of which only maggy in Magnaporthe grisea showed activity (Talbot, 1998).

Few copia group retroelements have been characterized, these elements being inactive due to multiple deletions and mutations in conserved regions. Among the copia retrotransposons so far identified is the tcen element in found in the centromeric regions of the filamentous fungus Neurospora crassa (Cambareri et al., 1998).

Several non-LTR retrotransposons have also been characterized. The tad element in $N$. crassa was the first transposon described in a fungus where it was found inserted in the glutamate dehydrogenase am gene (Kinsey and Helber, 1989), transposition of this element was having been demonstrated by transference between genetically marked nuclei in forced heterokaryons (Kinsey, 1993). Among the non-LTR retrotransposon of the LINE type (Table 1), only tad and $m g l$ are active elements.

In Colletotrichum gloeosporioides (an anthracnose filamentous fungi pathogenic for Stylosanthes spp) the cgt1 retrotransposon was isolated from the Stylosanthes B biotype but not from the A biotype and the same was observed for the Colletotrichum species lindemuthianum, trifolii and destructivum (He et al., 1996). The cgtl element is considered an important tool for the study of population structure, genome dynamics and evolution in C. gloeosporioides $(\mathrm{He}$ 
Table 1 - General classification of fungal class I transposable elements.

\begin{tabular}{|c|c|c|c|c|}
\hline Element class & Element group & Element $^{1}$ & Host fungus & References \\
\hline \multirow{31}{*}{$\begin{array}{l}\text { Class I transposons } \\
\text { (retroelements) }\end{array}$} & LTR retrotransposon & foret & Fusarium oxysporum & Julien et al., 1992 \\
\hline & Metaviridae (gypsy) & skippy & F. oxysporum & Anaya and Roncero, 1995 \\
\hline & & grh & Magnaporthe grisea & Dobinson et al., 1993 \\
\hline & & maggy & M. grisea & Farman et al., 1996b \\
\hline & & pyret & M. grisea & Nakayashiki et al., 2001 \\
\hline & & $m g l 3$ & M. grisea & Kang, 2001 \\
\hline & & $c f t-1$ & Cladosporium fulvum & McHale et al., 1992 \\
\hline & & cgret & Colletotrichum gloeosporioides & Zhu and Oudemans, 2000 \\
\hline & & boty & Botrytis cinerea & Diolez et al., 1995 \\
\hline & & real & Alternaria alternata & Kaneko et al., 2000 \\
\hline & & dane 1,2 & Aspergillus nidulans & Nielsen et al., 2001 \\
\hline & & afut & A. fumigatus & Neuvéglise et al., 1996 \\
\hline & & mars4 & Ascobolus immersus & Goyon et al., 1996 \\
\hline & & $d a b 1$ & Neurospora crassa & Bibbins et al., 1998 \\
\hline & & yeti & Podospora anserina & Hamann et al., 2000b \\
\hline & & maryl & Tricholoma matsutake & Murata and Yamada, 2000 \\
\hline & & prt1 & Phycomyces blakesleanus & Ruiz-Pérez et al., 1996 \\
\hline & LTR retrotransposon & mars 2,3 & A. immersus & Goyon et al., 1996 \\
\hline & Pseudoviridae (copia) & tcen & N. crassa & Cambareri et al., 1998 \\
\hline & & $n h t 2$ & Nectria haematococa & Shiflett et al., 2002 \\
\hline & non LTR retrotransposon & tad & N. crassa & Kinsey and Helber, 1989 \\
\hline & $(L I N E)$ & $m g l$ & M. grisea & Nishimura et al., 2000 \\
\hline & & $\operatorname{mgr} 583$ & M. grisea & Hamer et al., 1989 \\
\hline & & cgt1 & C. gloeosporioides & He et al., 1996 \\
\hline & & mars 1 & A. immersus & Goyon et al., 1996 \\
\hline & & mary 2 & T. matsutake & Murata et al., 2001 \\
\hline & non LTR retrotransposon & $n r s 1$ & N. haematococca & Kim et al., 1995 \\
\hline & $(S I N E)$ & foxy & F. oxysporum & Mes et al., 2000 \\
\hline & & mgsr 1 & M. grisea & Kachroo et al., 1995 \\
\hline & & egrl & Erysiphe graminis & Wei et al., 1996 \\
\hline & & egh1 & E. graminis & Rasmussen et al., 1993 \\
\hline
\end{tabular}

${ }^{1}$ Classification based on reviews by Daboussi, 1996; Kempken and Kück, 1998 and Daboussi and Capy, 2003. T. matsutake is a basidiomycete and P. blakesleeanus a zigomycete, the remaining species are ascomycetes.

et al., 1996). Among the retrotransposons of the SINE type already isolated (Table 1) the foxy element showed activity after gamma radiation treatment and subsequent new insertions (Mes et al., 2000).

The class II transposable elements (or DNA transposons) can be classified in four different superfamilies: Tcl/mariner, hAT, Mutator and MITEs (Daboussi and Capy, 2003). The Tcl/mariner superfamily is the most abundant, the most studied elements of this superfamily being the fot1 and impala transposons of Fusarium oxysporum (Daboussi et al., 1992; Daboussi and Langin, 1994; Langin et al., 1995; Fernandez et al., 1998; Hua-van et al., 1998; Deschamps et al., 1999; Migheli et al., 1999; Chiocchetti et al., 1999; Hua-van et al., 2000; Rosevitch and Kistler, 2000; Hua-van et al., 2001ab; Villalba et al., 2001; Daviére et al., 2001; Hua-van et al., 2002; Daboussi et al., 2002; Daboussi and Capy, 2003). Members of this superfamily have inverted terminal repetitions (TIRs) of variable size and a Thymine/adenine (TA) target site. This site is generally duplicated on excision of the transposon, leading to alteration in the DNA sequence of the donor site. It has been demonstrated that fot 1 is an autonomous element that codifies its own transposase that has a catalytic domain which cleaves the DNA strands. This transposon was active when introduced by transformation in $F$. oxysporum strains without the element (Daboussi et al., 1992; Migheli et al., 1999).

The activity of the fot 1 and impala transposons and of other elements has been shown by chromosome rearrangements detected by analysis of the electrophoretic karyotype, this analysis also showing a grouping of transposons in some regions and a correlation between the high level of chromosome polymorphisms and transposable element concentration (Davière et al., 2001). In F. oxysporum chromosome duplications and gene rearrangements of the skippy LTR retrotransposon were also induced by growth under nutritional stress in the presence of potassium chlorate (Anaya and Roncero, 1996). The fot 1 and impala elements have also been used to asses the genetic diversity of $F$. oxysporum isolates from different French soils (Edel et al., 2001).

Villalba et al (2001) introduced the impala element into M. grisea where transposition of the element was revealed by excision of the niaD gene promoter and molecular analysis of the revertents using hybridization and sequencing. One mycelial growth mutant and a non- 
pathogenic mutant were isolated and it was shown that by insertion of the impala element a pathogenicity gene could be cloned and sequenced (ORP1) which is essential for the penetration of $M$. grisea into the host leaf tissue. This gene did not present homology with known genes, showing the potential of transposable elements for cloning of pathogenicity genes. In addition to the elements described above other transposons of the Tc1/mariner superfamily are described in Table 2.

The $h A T$ superfamily was defined based on the similarity between the maize $A c$ elements and the hobo element of Drosophila. This superfamily is well represented in fungi, and has been identified in both the Ascomycota and Basidiomycota (square 2). Elements belonging to the Mutator superfamily were identified recently in fungi by Chalvet et al (2003), which is very interesting because these elements had previously been detected only in plants. This element, called hop, was identified in the $F$. oxysporum genome as being active and similar to the elements found in maize.

The category of small elements with terminal inverted repetitions, called miniature inverted-repeat transposable elements (MITE) includes the F. oxysporum mimp elements (Hua-Van et al., 2000) and the guest element of on N. crassa (Yeadon and Catcheside, 1995). These elements are remainders of non-autonomous DNA transposons and their mobilization depends on the transposase produced by other class II elements (Feschottes et al., 2002).

\section{Identification Strategies for Transposable Elements}

Different strategies can be used to identify transposable elements in fungi:

I) Identification and cloning of dispersed repeated sequences. Several transposons have been cloned and identified by comparison with elements described in other organisms but this method does not show whether these sequences remain active. This strategy is particularly appropriate to identify high copy number transposons regardless of their activity (Kempken and Kück, 1998). Some examples of elements identified by this strategy are the foret 1 and palm transposons of $F$. oxysporum (Julien et al., 1992; Mouyna et al., 1996) and the cgt1 and cgret elements of $C$. gloeosporioides (He et al., 1996; Zhu and Oudemans, 2000).

Table 2 - General classification of fungal class II transposable elements.

\begin{tabular}{|c|c|c|c|c|}
\hline Element class & Element superfamily & Elements $^{1}$ & Host fungus & References \\
\hline \multirow{29}{*}{$\begin{array}{l}\text { Class II transposons } \\
\text { (DNA mediated ele- } \\
\text { ments) }\end{array}$} & \multirow[t]{16}{*}{ Tc1/Mariner } & fot1 & Fusarium oxysporum & Daboussi et al., 1992 \\
\hline & & impala & F. oxysporum & Langin et al., 1995 \\
\hline & & fot 2 & F. oxysporum & Daboussi and Langin, 1994 \\
\hline & & fot $3 ;$ fot 4 & F. oxysporum & Hua-van et al., 2000 \\
\hline & & punt & Neurospora crassa & Margolin et al., 1998 \\
\hline & & flipper & Botrytis cinerea & Levis et al., 1997 \\
\hline & & $\tan 1$ & Aspergillus niger & Nyyssonen et al., 1996 \\
\hline & & vader & A. niger & Amutan et al., 1996 \\
\hline & & ant1 & A. niger & Glayzer et al., 1995 \\
\hline & & pot2 & Magnaporthe grisea & Kachroo et al., 1994 \\
\hline & & $\operatorname{mgr} 586$ & M. grisea & Farman et al., 1996a \\
\hline & & $f c c 1$ & Cochliobolus carbonum & Panaccione et al., 1996 \\
\hline & & nht1 & Nectria haematococa & Enkerli et al., 1997 \\
\hline & & pat & Podospora anserina & Hamann et al., 2000a \\
\hline & & hupfer & Beauveria bassiana & Maurer et al., 1997 \\
\hline & & pcel & Phanerochaete chrysosporium & Gaskell et al., 1995 \\
\hline & \multirow[t]{10}{*}{$h A T$} & restless & Tolypocladium inflatum & Kempken and Kück, 1996 \\
\hline & & folyt & F. oxysporum & Gómez-Gómez et al., 1999 \\
\hline & & tfol & F. oxysporum & Okuda et al., 1998 \\
\hline & & hornet 1,2,3 & F. oxysporum & Hua-Van et al., 2000 \\
\hline & & palm & F. oxysporum & Mouyna et al., 1996 \\
\hline & & crypt 1 & Cryphonectria parasitica & Linder-Basso et al., 2001 \\
\hline & & ascot & Ascobolus immersus & Colot and Rossignol, 1995 \\
\hline & & tasco & A. immersus & Goyon et al., 1996 \\
\hline & & scooter & Schizophyllum comune & Fowler and Mitton, 2000 \\
\hline & & $a b r 1$ & Agaricus bisporus & Sonnenberg et al., 1999 \\
\hline & Mutator & hop & F. oxysporum & Chalvet et al., 2003 \\
\hline & \multirow[t]{2}{*}{ MITE } & $\operatorname{mimp}$ & F. oxysporum & Hua-van et al., 2000 \\
\hline & & guest & N. crassa & Yeadon and Catcheside, 1995 \\
\hline
\end{tabular}

${ }^{1}$ Classification based in previous reviews of Daboussi, 1996; Kempken and Kück, 1998 and Daboussi and Capy, 2003. S. commune, A. bisporus and P. chrysosporium are basidiomycetes, all other species are ascomycetes. 
II) Spontaneous inactivation of cloned genes. This is the most satisfactory strategy for identifying active transposons and is generally applied to genes whose mutant phenotype can be positively selected. This is the case of mutations in the nitrate reductase structural gene, which can be selected for resistance to chlorate (Cove, 1976ab; Cove, 1979). This gene is particularly appropriate because it can be selected for transposon integration or excision. The transposable elements of such mutants can be identified by PCR. This method is suitable for identifying elements with high excision and insertion frequencies (Kempken and Kück, 1998). Examples of transposons cloned by spontaneous mutation selection in the nitrate reductase gene include fot 1 in $F$. oxysporum (Daboussi et al., 1992); impala in F. oxysporum (Langin et al., 1995); ant1 in Aspergillus niger (Glayzer et al., 1995); vader in A. niger var. awamori (Amutan et al., 1996); flipper in Botrytis cinerea (Levis et al., 1997); hupfer in Beauveria bassiana (Maurer et al., 1997); and folyt1 in F. oxysporum (Gómez-Gómez et al., 1999).

III) Construction of degenerated oligonucleotides of conserved domains of reverse transcriptase and transposases. A particularly useful method for identifying class I elements (reverse transcriptase method) and class II elements (transposase method). The advantage of this strategy is that it permits the rapid analysis of a large number of organisms (Kempken and Kück, 1998) as described for the isolation of the yeti transposon in Podospora anserina (Hamman et al., 2000b).

IV) Use of heterologous probes in hybridization experiments. This method requires appropriate probes and only detects known transposons (Kempken and Kück, 1998). An example is the isolation of the skippy element of $F$. oxysporum by hybridization with the $c f t 1$ element of Cladosporium fulvum (Anaya and Roncero, 1995).

\section{Effects of Transposable Elements on Genes and Genomes}

The main alterations caused by these elements include changes in gene expression due to insertion in, or adjacent to, the genes, which can create a new phenotype due to blocked transcription of associated genes or alteration in the transcription pattern. Transposable elements can also change the gene sequence due to the 'footprints' generated in the donor site on excision of the transposable element and chromosome rearrangements such as deletions, inversions and translocations. These rearrangements can occur especially if the elements are present in more than one copy, because they can generate sites of reciprocal recombination leading to alterations in the chromosome structure (Daboussi, 1996). Karyotypic instability has been investigated in species carriers of many families of transposons such as $F$. oxysporum and $M$. grisea. The analysis of the karyotypic instability showed a high level of chromosome length polymorphism with a high density of transposons and that the occurrence of chromosome rearrangements is associated with the clustering of transposable elements on the chromosomes (Davière et al., 2001; Hua-van et al., 2000; Nitta and Farman, 1997). These changes are reported as being genetically neutral, but can also lead to genetic combinations important for adaptation to new environments. All these changes have potential for influencing many aspects of the evolution of the fungal genome and should supply the flexibility for the populations to adapt successfully to environmental conditions.

\section{Control of Transposable Element Activity}

In spite of the abundance of transposable elements in the genome, most eukaryotic elements only move sporadically (Fedoroff, 2002). Regulatory pathways controlled by the host and transposons act on the regulation of the transposition. In animals and plants, transposon control has been shown at different levels, revealing that these elements are generally quiescent during growth and development, but can be activated by stress (Capy et al., 2000; Grandbastien, 1998; Wessler, 1996). Little is known about the mechanisms that control the activity of transposable elements in fungi, although recent evidence shows that they can be activated by stress and silenced by epigenetic processes.

Transposition as a response to environmental stress was proposed as an adaptive response of the genome (McClintock, 1984). Several transposons in plants, yeasts and Drosophila show activity under conditions of abiotic (irradiation, temperature, oxidative stress) or biotic (tissue culture, infection by pathogens or protoplast isolation) stress (Capy et al., 2000; Grandbastien, 1998; Wessler, 1996). Some of the factors that stimulate transposition have been tested on fungi, e.g. heat shock, copper sulfate and oxidative stress act on maggy retrotransposons in $M$. grisea (Ikeda et al., 2001); gamma radiation increased the number of copies of the SINE element foxy in F. oxysporum (Mes et al., 2000); and exposure to chlorate activated rearrangement and induced skippy retrotransposon amplification in Fusarium (Anaya and Roncero, 1996).

Several inactivation mechanisms of repeated sequences have been revealed in some species such as $N$. crassa, Ascobolus immersus and M. grisea (Cogoni, 2001; Faugeron, 2000; Selker, 1999; Ikeda et al., 2002). A repeat-induced point mutation (RIP) in A. immersus inactivated native or foreign linked or non-linked duplicate sequences during a specific period of the sex cycle between fertilization and kariogamy. This inactivation was associated with the cytosine methylation of duplicated sequences. The RIP process results in many base pair C-G for A-T changes and is irreversible. The methylation-induced point mutation (MIP) process inactivates genes reversibly by cytosine methylation.

These genetic silencing mechanisms can be considered as defense strategies which control invader trans- 
posons. Transposable elements are natural targets for such mechanisms, and silencing may prevent invasion of the genome, methylation suppression of recombination and also the rapid divergence caused by RIP, thus preventing the recombination among repeated sequences and protecting the genome against gross chromosome rearrangements. Consistent with this interpretation, only remaining of transposons have been detected in N. crassa and A. immersus. The RIP and MIP processes may not be common to all fungi but signs of the RIP processes in some species may reflect the occurrence of this process in an ancestral or cryptic sexual stage, or the existence of a similar process to RIP in vegetative cells (Daboussi and Capy, 2003).

\section{Transposable Element Dynamics in the Genome}

The phylogenetic distribution and analysis of transposable elements in the main fungus groups, Ascomycota, Basidiomycota and Zygomycota suggest that they are old components of the fungal genome transmitted vertically, although the possibility of horizontal transmission should not be discarded as has been reported in several studies. The sporadic distribution of some elements and the variation in copy number reflect competition among elements, elimination, self regulation and regulation by the host. These aspects, along with the extensive DNA polymorphism which often occurs, have been used to investigate population structure and epidemiology of fungal pathogenic strains.

The dynamics of fungal transposons have been extensively analyzed in F. oxysporum, the fot 1 element being present in most of $F$. oxysporum strains with a copy number varying from zero to more than 100 . The phylogeny of this element indicates that it is an old component of the genome and transferred vertically. The high number of homogeneous copies for structure and sequences of nucleotides probably reflects a recent amplification from a master copy. Regarding the $F$. oxysporum impala element, highly divergent families with a constant number of copies coexist in the genome (Hua-van et al., 1998). These facts indicate that transposons can be kept in the host genome by different strategies. The absence of copies in various strains of $F$. oxysporum is probably due to elimination by natural selection and/or genetic drift. Other factors, such as rearrangements and silencing mechanisms may be involved in transposon dynamics leading to their reduction or inactivation, although this may be counterbalanced by the introduction of new elements by horizontal transmission (Dobinson et al., 1993; Daboussi et al., 2002).

\section{Transposable Elements as Genetic Tools: Gene Isolation and Analysis of Population Structure}

Transposons act as insertional mutagens and genes altered in this way can be cloned as sequences that flank the transposon insertion sites and are part of the gene of interest (Daboussi, 1996). The fot 1 and impala elements in $F$. oxysporum, restless in Tolypocladium inflatum, and maggy in $M$. grisea are autonomous elements that have been used as gene traps in their natural hosts and tested for their transposition skill in heterologous species. The use of transposons for gene cloning can be exemplified by the cloning of a nitrate metabolism regulator gene in Tolypocladium inflatum (Kempken and Kück, 2000). A high proportion of mutant in $F$. oxysporum was recovered by impala transposition, showing the efficiency of transposition in pathogenicity mutant generation of the fungi (Migheli et al., 2000).

The elements of the Tc1/mariner family, fot 1 and impala, have also been tested in different species. The fot 1 transposition was demonstrated in A. nidulans (Li Destri et al., 2001) while the impala element is capable of transposition in several ascomycetes species, for example $F$. moniliforme (Hua-van et al., 2001b), M. grisea (Villalba et al., 2001), A. nidulans (Li Destri et al., 2001), A. fumigatus (Firon et al., 2003), C. gloeosporioides (Li Destri et al., 2002), and P. griseoroseum (De Queiroz and Daboussi, 2003). The isolation of genes of interest, such as a gene involved in M. grisea pathogenicity (Villalba et al., 2001), genes involved in A. nidulans development and metabolism (Brocard-Masson, 2001) and different genes essential for the growth of A. fumigatus (Firon et al., 2003) support the development of insertional mutagenesis tools in filamentous fungi. Other elements have also shown activity in heterologous species, e.g. maggy in Colletotrichum lagenarium and Pyricularia zingheri (Nakayashiki et al., 1999) and restless in $N$. crassa and P. chrysogenum (Windhofer et al., 2002).

Transposons, in addition to use as tools for cloning genes of interest, have also been used as markers for detection of specific races of phytopathogenic fungi in infected plant tissues and in the study of population dynamics and evolution (Daboussi and Langin, 1994; Daboussi and Capy, 2003). From the epidemiological point of view, it is important to understand how the specific populations of determined hosts are organized and how they are altered. For this, the conservation and dispersion of transposable elements in these fungi have given important markers in the study of biology of pathogen populations in plants and animals.

Transposons have been used to distinguish genetically divergent populations because they can mark specific genotypes that have a common ancestor (Dobinson et al., 1993; Giraud et al., 1997; He et al., 1996; Kachroo et al., 1994; Mouyna et al., 1996; Shull and Hamer, 1996; Zhu and Oudemans, 2000). In F. oxysporum f. sp. Elaeidis (an oil palm pathogen) the palm transposon was used to identify subpopulations of the pathogen, showing that the recent appearance of the disease in South America probably occurred by the introduction of an African isolate. This study also showed the presence of the palm element in all the 
pathogenic isolates, and its absence in all the nonpathogenic isolates, indicating that populations may be marked by transposons (Mouyna et al., 1996).

Diagnostic tools based on PCR were developed to detect pathogenic $F$. oxysporum races causing carnation wilt. This strategy is based on the genetic characterization of a collection of strains using different transposons and in the cloning and sequencing of regions that flank insertion sites of these elements. Those seemingly related to a specific race or pathogenic form are used to construct specific primers for fast pathogen identification (Chiocchetti et al., 1999). Analysis of Pyricularia grisea populations using different transposable elements has led to the understanding of the evolution of host-specific forms, showing the clonal organization of $P$. grisea populations that infect rice and the possibility of new strains of the pathogen emerging as independent strains (Dobinson et al., 1993; Kachroo et al., 1994; Shull and Hamer, 1996).

\section{Conclusions}

Many types of transposable elements have been described in several fungi species, indicating that they are old components of their genomes. With the genome sequencing of different Ascomycota and Basidiomycota species, new transposons will continue to be discovered. Genomic analysis will be very useful for understanding the impact of transposons on the evolution of the fungal genome and also for the development of better diagnostic tools. The study of transposons in fungi has contributed to the understanding of important questions concerning their biology, such as genetic silencing and movement mechanisms. Another important point is the isolation of genes by the transposon trap strategy. New tools are being developed using transposon engineering. Furthermore, because many fungi (along with some algae) are coenocytic such organisms represent a unique environment for transposable elements and can contribute to the study of horizontal genetic transference processes in diverse species.

\section{Acknowledgments}

The authors thank the Brazilian National Council for the Development of Science and Technology (CNPq) for financial support.

\section{References}

Amutan M, Nyyssonem E, Stubbs J, Diaz-Torres MR and DunnColeman N (1996) Identification and cloning of a mobile transposon from Aspergillus niger var. awamori. Curr Genet 29:468-473

Anaya N and Roncero MIG (1995) Skippy, a retrotransposon from the fungal plant pathogen Fusarium oxysporum. Mol Gen Genet 249:637-647.

Anaya N and Roncero MIG (1996) Stress-induced rearrangement of Fusarium retrotransposon sequences. Mol Gen Genet 253:89-94.
Bibbins M, Cummings NJ and Connerton IF (1998) Dabl: A degenerate retrotransposon-like element from Neurospora crassa. Mol Gen Genet 258:431-436.

Boeke JD (1989) Transposable elements in Saccharomyces cerevisiae. In: Berg DE and M Howe (eds) Mobile DNA. ASM, Washington DC, pp 335-374.

Brocard-Masson C (2001) Transposition hétérologue chez Aspergillus nidulans. $\mathrm{PhD}$ thesis, Univ. Paris, France.

Cambareri EB, Aisner R and Carbon J (1998) Structure of the chromosome VII centromere in Neurospora crassa: Degenerate transposons and simple repeats. Mol Cell Biol 18:5465-5477.

Capy P, Gasperi G, Biemont C and Bazin C (2000) Stress and transposable elements: Co-evolution or useful parasites? Heredity 85:101-106.

Chalvet F, Grimaldi C, Kaper F, Langin T and Daboussi MJ (2003) Hop, an active Mutator-like element in the genome of the fungus Fusarium oxysporum. Mol Biol Evol 20:1362-1375.

Chiocchetti A, Bernardo I, Daboussi MJ, Garibaldi A and Gullino ML (1999) Detection of Fusarium oxysporum f. sp. dianthi in carnation tissue by PCR amplification of transposon insertions. Phytopathology 89:1169-1175.

Cogoni C (2001) Homology-dependent gene silencing mechanisms in fungi. Annu Rev Microbiol 55:381-406.

Colot V and Rossignol JL (1995) Isolation of the Ascobolus immersus spore color gene b2 and study in single cells of gene silencing by methylation induced premeiotically. Genetics 141:1299-1314.

Cove DJ (1976 a) Chlorate toxicity in Aspergillus nidulans: The selection and characterization of chlorate resistant mutants. Heredity 36:191-203.

Cove DJ (1976 b) Chlorate toxicity in Aspergillus nidulans: Studies of mutants in nitrate assimilation. Mol Gen Genet 146:147-159.

Cove DJ (1979) Genetic studies of nitrate assimilation in Aspergillus nidulans. Biological Reviews 54:291-327.

Daboussi MJ, Langin T and Brygoo Y (1992) Fot1, a new family of fungal transposable elements. Mol Gen Genet 232:12-16.

Daboussi MJ (1996) Fungal transposable elements: Generators of diversity and genetic tools. J Genet 75:325-339.

Daboussi MJ and Langin T (1994) Transposable elements in the fungal plant pathogen Fusarium oxysporum. Genetica 93:49-59.

Daboussi MJ (1997) Fungal transposable elements and genome evolution. Genetica 100:253-260.

Daboussi MJ, Davière JM, Graziani S and Langin T (2002) Evolution of the fot 1 transposons in the genus Fusarium: Discontinuous distribution and epigenetic inactivation. Mol Biol Evol 19:510-520.

Daboussi MJ and Capy P (2003) Transposable elements in filamentous fungi. Annu Rev Microbiol 57:275-299.

Davière JM, Langin T and Daboussi MJ (2001) Potential role of transposable elements in the rapid reorganization of the Fusarium oxysporum genome. Fungal Genet Biol 34:177192.

De Queiroz MV and Daboussi MJ (2003) Impala, a transposon of Fusarium oxysporum, is active in the genome of Penicillium griseoroseum. FEBS Microbiol Lett 218:317-321.

Deschamps F, Langin T, Maures P, Gerlinger C, Felenbok B and Daboussi MJ (1999) Specific expression of the Fusarium 
transposon fot 1 and effects on target gene transcription. Mol Microbiol 31:1373-1383.

Decaris B, Francou F, Lefort C and Rizet G (1978) Unstable ascospore color mutants of Ascobolus immersus. Mol Gen Genet 162:69-81.

Diolez A, Marches F, Fortini D and Brygoo Y (1995) Boty, a long-terminal-repeat retroelement in the phytopathogenic fungus Botrytis cinerea. Appl Environ Microbiol 61:103-108.

Dobinson KF, Harris RE and Hamer JE (1993) Grasshopper, a long terminal repeat (LTR) retroelement in the phytopathogenic fungus Magnaporthe grisea. Mol Plant-Microbe Interact 6:114-126.

Edel V, Steinberg C, Gautheron N, Recorbet G and Alabouvette C (2001) Genetic diversity of Fusarium oxysporum populations isolated from different soils in France. FEMS Microbiol Ecol 36:61-67.

Enkerli J, Bhatt G and Covert SF (1997) Nht1, a transposable element cloned from a dispensable chromosome in Nectria haematococca. Mol Plant-Microbe Interact 10:742-749.

Farman ML, Taura S and Leong AS (1996 a) The Magnaporthe grisea fingerprinting probe MGR586 contains the 3' end of an inverted repeat transposon. Mol Gen Genet 251:675-681.

Farman ML, Tosa Y, Nitta N and Leong SA (1996 b) MAGGY, a retrotransposon in the genome of the rice blast fungus Magnaporthe grisea. Mol Gen Genet 251:665-674.

Faugeron G (2000) Diversity of homology-dependent gene silencing strategies in fungi. Curr Opin Microbiol 3:144-148.

Fedoroff N (2002) Control of mobile DNA. In: Craig NL, Craigie R, Gellert M and Lambowitz AM (eds) Mobile DNA II. ASM, Washington DC, pp 907-1007.

Fernandez D, Ouinten M, Tantaoui A, Geiger JP, Daboussi MJ and Langin T (1998) Fot1 insertions in the Fusarium oxysporum f. sp. albedinis genome provide diagnostic PCR targets for detection of the date palm pathogen. Appl Environ Microbiol 64:633-636.

Feschottes C, Zhang X and Wessler SR (2002) Miniature inverted-repeat transposable elements and their relationship to established DNA transposons. In: Craig NL, Craigie R, Gellert M and Lambowitz AM (eds) Mobile DNA II. ASM, Washington DC, pp 1147-1158.

Finnegan DJ (1989) Eukaryotic transposable elements and genome evolution. Trends Genet 5:103-107.

Firon A, Villalba F, Beffa R and D'enfert C (2003) Identification of essential genes in the human fungal pathogen Aspergillus fumigatus by transposon mutagenesis. Eukariot Cell 2:247255.

Fowler TJ and Mitton MF (2000) Scooter, a new active transposon in Schizophyllum commune, has disrupted two genes regulating signal transduction. Genetics 156:1585-1594.

Gaskell J, Van Den Wymelenberg A and Cullen D (1995) Structure, inheritance, and transcriptional effects of pcel, an insertional element within Phanerochaete chrysosporium lignin peroxidase gene lipI. Proc Natl Acad Sci USA 92:7465-7469.

Giraud T, Fortini D, Levis C, Leroux P and Brygoo Y (1997) RFLP markers show genetic recombination in Botryotinia fuckeliana (Botrytis cinerea) and transposable elements reveal two sympatric species. Mol Biol Evol 14:1177-1185.
Glayzer DC, Roberts IN, Archer DB and Oliver RP (1995) The isolation of ant1, a transposable element from Aspergillus niger. Mol Gen Genet 249:432-438.

Gómez-Gómez E, Anaya N, Roncero MI and Hera C (1999) Folyt 1, a new member of the $h A T$ family, is active in the genome of the plant pathogen Fusarium oxysporum. Fungal Genet Biol 27:67-76.

Goyon C, Rossignol JL and Faugeron G (1996) Native DNA repeats and methylation in Ascobolus. Nucleic Acids Res 24:3348-3356.

Grandbastien MA (1998) Activation of plant retrotransposons under stress conditions. Trends Plant Sci 3:181-187.

Hamann A, Feller F and Osiewacz HD (2000a) The degenerate DNA transposon pat and repeat-induced point mutation (RIP) in Podospora anserina. Mol Gen Genet 263:10611069.

Hamann A, Feller F and Osiewacz HD (2000b) Yeti-a degenerate gypsy-like LTR retrotransposon in the filamentous ascomycete Podospora anserina. Curr Genet 38:132-140.

Hamer JE, Farrall L, Orbach MJ, Valent B and Chumley FG (1989) Host species-specific conservation of a family of repeated sequences in the genome of a fungal plant pathogen. Proc Natl Acad Sci USA 86:9981-9985.

Havecker ER, Gao X and Voytas DF (2004) The diversity of LTR retrotransposons. Genome Biol 5:225-225.6.

He C, Nourse JP, Kelemu S, Irwin JÁ and Manners JM (1996) Cgt1: A non-LTR retrotransposon with restricted distribution in the fungal phytopathogen Colletotrichum gloeosporioides. Mol Gen Genet 252:320-331.

Hua-Van A, Daviere JM, Langin T and Daboussi MJ (2000) Genome organization in Fusarium oxysporum: Clusters of class II transposons. Curr Genet 37:339-347.

Hua-Van A, Héricourt F, Capy P, Daboussi MJ and Langin T (1998) Three highly divergent subfamilies of the impala transposable element coexist in the genome of the fungus Fusarium oxysporum. Mol Gen Genet 259:354-362.

Hua-Van A, Langin T and Daboussi MJ (2001a) Evolutionary history of the impala transposon in Fusarium oxysporum. Mol Biol Evol 18:1959-1969.

Hua-Van A, Langin T and Daboussi MJ (2002) Aberrant transposition of a Tc1-mariner element, impala, in the fungus Fusarium oxysporum. Mol Genet Genomics 267:79-87.

Hua-Van A, Pamphile JÁ, Langin T and Daboussi MJ (2001b) Transposition of autonomous and engineered impala transposons in Fusarium oxysporum and a related species. Mol Gen Genet 264:724-731.

Ikeda K, Nakayashiki H, Kataoka T, Tamba H and Hashimoto Y (2002) Repeated-induced point mutation (RIP) in Magnaporthe grisea: Implications for its sexual cycle en the natural field context. Mol Microbiol 45:1355-1364.

Ikeda K, Nakayashiki H, Takagi M, Tosa Y and Mayama S (2001) Heat shock, coper sulfate and oxidative stress activate the retrotransposon MAGGY resident in the plant pathogenic fungus Magnaporthe grisea. Mol Genet Genomics 266:318-325.

Julien J, Poirier-Hamon S and Brygoo Y (1992) Foret1, a reverse transcriptase-like sequence in the filamentous fungus Fusarium oxysporum. Nucleic Acids Res 20:3933-3937.

Kachroo P, Leong AS and Chattoo BB (1994) Pot2, an inverted repeat transposon from the rice blast fungus Magnaporthe grisea. Mol Gen Genet 245:339-348. 
Kachroo P, Leong AS and Chattoo BB (1995) Mg-SINE: A short interspersed nuclear element from the rice blast fungus Magnaporthe grisea. Proc Natl Acad Sci USA 92:1112511128.

Kaneko I, Tanaka A and Tsuge T (2000) REAL, an LTR retrotransposon from the plant pathogenic fungus Alternaria alternata. Mol Gen Genet 263:625-634.

Kang S (2001) Organization and distribution pattern of MGLR-3, a novel retrotransposon in the rice blast fungus Magnaporthe grisea. Fungal Genet Biol 32:11-19.

Kempken F and Kück U (1998) Transposons in filamentous fungi - Facts and perspectives. BioEssays 20:652-659.

Kempken F and Kück U (1996) Restless, an active Ac-like transposon from the fungus Tolypocladium inflatum: Structure, expression, and alternative RNA splicing. Mol Cell Biol 16:6563-6572.

Kempken F and Kück U (2000) Tagging of a nitrogen pathway-specific regulator gene in Tolypocladium inflatum by the transposon Restless. Mol Gen Genet 263:302-308.

Kim HG, Meinhardt LW, Benny U and Kistler HC (1995) Nrs 1, a repetitive element linked to pisatin demethylase genes on a dispensable chromosome of Nectria Haematococca. Mol Plant-Microbe Interact 8:524-531.

Kinsey JA and Helber J (1989) Isolation of a transposable element from Neurospora crassa. Proc Natl Acad Sci USA 86:1929-1933.

Kinsey JA (1993) Transnuclear retrotransposition of the tad element of Neurospora. Proc Natl Acad Sci USA 90:93849387.

Kistler HC and Miao VP (1992) New modes of genetic change in filamentous fungi. Annu Rev Phytopathol 30:131-152.

Langin T, Capy P and Daboussi MJ (1995) The transposable element impala, a fungal member of the Tc1-mariner super family. Mol Gen Genet 246:19-28.

Levis C, Fortini D and Brygoo Y (1997) Flipper, a mobile fot1like transposable element in Botrytis cinerea. Mol Gen Genet 254:674-680.

Li Destri Nicosia MG, Brocard-Masson C, Demais S, Hua-Van A, Daboussi MJ and Scazzocchio C (2001) Heterologous transposition in Aspergillus nidulans. Mol Microbiol 39:13301344.

Li Destri Nicosia MG, Hua-Van A, Cacciola S and Daboussi MJ (2002) Transposition of impala as a potential tool for insertional mutagenesis in Colletotrichum gloeosporioides. Abstracts of $6^{\text {th }}$ Eur Conf on Fungal Genetics, pp 112.

Linder-Basso K, Foglia R, Zhu P and Hillman BI (2001) Crypt1, an active Ac-like transposon from the chestnut blight fungus, Cryphonectria parasitica. Mol Genet Genomics 265:730-738.

Margolin BS, Garrett-Engele PW, Stevens JN, Fritz DY and Garret-Engele C (1998) A methilated Neurospora 5S rRNA pseudogene contains a transposable element inactivated by repeat-induced point mutation. Genetics 149:1787-1797.

Maurer P, Rejasse A, Capy P, Langin T and Riba G (1997) Isolation of the transposable element hupfer from the entomopathogenic fungus Beauveria bassiana by insertion mutagenesis of the nitrate reductase structural gene. Mol Gen Genet 256:195-202.

Mcclintock B (1984) The significance of responses of the genome to challenge. Science 226:792-801.
Mc Hale MT, Roberts IN, Noble SM, Beaumont C and Whitehead MP (1992) Cft-I: An LTR-retrotransposon in Cladosporium fulvum, a fungal pathogen of tomato. Mol Gen Genet 233:337-347.

Mes JJ, Haring MA and Cornelissen BJ (2000) Foxy: An active family of short interspersed nuclear elements from Fusarium oxysporum. Mol Gen Genet 263:271-280.

Migheli Q, Laugé R, Daviere JM, Gerlinger C and Kaper F (1999) Transposition of the autonomous fot 1 element in the filamentous fungus Fusarium oxysporum. Genetics 151:10051013.

Migheli Q, Steinberg C, Daviere JM, Olivain C and Gerlinger C (2000) Recovery of mutants impaired in pathogenicity after transposition of impala in Fusarium oxysporum f. sp. melonis. Phytopathology 90:1279-1284.

Mouyna I, Renard JL and Brygoo Y (1996) DNA polymorphism among Fusarium oxysporum f. sp. elaeidis populations from oil palm, using a repeated and dispersed sequence "Palm". Curr Genet 30:174-180.

Murata H, Miyazaki Y and Yamada A (2001) MarY2n, a LINElike non-long terminal repeat (non-LTR) retroelement from the ectomycorrhizal homobasidiomycete Tricholoma matsutake. Biosci Biotechnol Biochem 62:2301-2305.

Murata H and Yamada A (2000) MarY1, a member of the gypsy group of long terminal repeat retroelements from the ectomycorrhizal homobasidiomycete Tricholoma matsutake. Appl Environ Microbiol 66:3642-3645.

Nakayashiki H, Kiyotomi K, Tosa Y and Mayama S (1999) Transposition of the retrotransposon MAGGY in heterologous species of filamentous fungi. Genetics 153:693-703.

Nakayashiki H, Matsuo H, Chuma I, Ikeda K and Betsuyaku S (2001) Pyret, a Ty3/Gypsy retrotransposon in Magnaporthe grisea contains an extra domain between the nucleocapsid and protease domains. Nucleic Acids Res 29:4106-4113.

Neuvéglise C, Sarfati J, Latgé JP and Paris S (1996) Afut1, a retrotransposon-like element from Aspergillus fumigatus. Nucleic Acids Res 24:1428-1434.

Nielsen ML, Hermansen TD and Aleksenko A (2001) A family of DNA repeats in Aspergillus nidulans has assimilated degenerated retrotransposons. Mol Genet Genomics 265:883-887.

Nishimura M, Hayashi N, Jwa NS, Lau GW, Hamer JE and Hasebe A (2000) Insertion of the LINE retrotransposon MGL causes a conidiophore pattern mutation in Magnaporthe grisea. Mol Plant-Microbe Interact 13:892894.

Nitta N and Farman ML (1997) Genome organization of Magnaporthe grisea: Integration of genetic maps, clustering of transposable elements and identification of genome duplications and rearrangements. Theor Appl Genet 95:20-32.

Nyyssönen E, Amutan M, Enfield L, Stubbs J and Dunn-Coleman NS (1996) The transposable element tan1 of Aspergillus niger var. awamori, a new member of the fot 1 family. Mol Gen Genet 253:50-56.

Okuda M, Ikeda K, Namiki F, Nishi K and Tsuge T (1998) Tfo1: An Ac-like transposon from the plant pathogenic fungus Fusarium oxysporum. Mol Gen Genet 258:599-607.

Oliver RP (1992) Transposons in filamentous fungi. In: Stahl U and Tudzynski P (eds) Molecular Biology of Filamentous Fungi. Proceedings of the EMBO-Workshop, VCH, Berlin, pp 3-11. 
Panaccione DG, Pitkin JW, Walton JD and Annis SL (1996) Transposon-like sequences at the TOX2 locus of the plant-pathogenic fungus Cochliobolus carbonum. Gene 176:103-109.

Rasmussen M, Rossen L and Giese H (1993) SINE-like properties of a highly repetitive element in the genome of the obligate parasitic fungus Erysiphe graminis f. sp. hordei. Mol Gen Genet 239:298-303.

Rosevitch UL and Kistler HC (2000) Role of horizontal gene transfer in the evolution of fungi. Annu Rev Phytopathol 38:325-363.

Ruiz-Pérez VL, Murillo FJ and Torres-Martínez S (1996) Prt1, an unusual retrotransposon-like sequence in the fungus Phycomyces blakesleeanus. Mol Gen Genet 253:324-333.

Selker EU (1999) Epigenetic phenomena in filamentous fungi: Useful paradigms or repeated-induced confusion? Trends Genet 13:296-301.

Shiflett AM, Enkerli J and Covert SF (2002) Nht2, a copia LTR retrotransposon from a conditionally dispensable chromosome in Nectria haematococca. Curr Genet 41:99-106.

Shull VK and Hamer JE (1996) Genetic differentiation in the rice blast fungus revealed by the distribution of the Fosbory retrotransposon. Fungal Genet Biol 20:59-69.

Sonnenberg AS, Baars JJ, Mikosch TS, Schaap PJ and Van Griensven LJ (1999) Abr1, a transposon-like element in the genome of the cultivated mushroom Agaricus bisporus (Lange) Imbach. Appl Environ Microbiol 65:3347-3353.
Talbot NJ (1998) Molecular variability of fungal pathogens: Using the rice blast fungus as a case study. In: Bridge P, Couteaudier Y and Clarkson J (eds) Molecular Variability of Fungal Pathogens. CAB International, Oxon, pp 1-18.

Villalba F, Lebrun MH, Hua-Van A, Daboussi MJ and GrosjeanCournoyer MC (2001) Transposon impala, a novel tool for gene tagging in the rice blast fungus Magnaporthe grisea. Mol Plant-Microbe Interact 14:308-315.

Wei YD, Collinge DB, Smedegaard-Petersen V and ThordalChristensen H (1996) Characterization of the transcript of a new class of retroposon-type repetitive element cloned from the powdery mildew fungus Erysiphe graminis. Mol Gen Genet 250:477-482.

Wessler SR (1996) Turned on by stress. Plant retrotransposons. Curr Biol 6:959-961.

Windhofer F, Hauck K, Catcheside DE, Kuck U and Kempken F (2002) Ds-like restless deletion derivatives occur in Tolypocladium inflatum and two foreign hosts, Neurospora crassa and Penicillium chrysogenum. Fungal Genet Biol 35:171-182.

Yeadon PJ and Catcheside DE (1995) Guest: A 98pb inverted repeat transposable element in Neurospora crassa. Mol Gen Genet 247:105-109.

Zhu P and Oudemans PV (2000) A long terminal repeat retrotransposon cgret from the phytopathogenic fungus Colletotrichum gloeosporioides on cranberry. Curr Genet 38:241-247.

Associate Editor: Sérgio Olavo Pinto da Costa 